\title{
Supervisory control of operation of a cogeneration plant using fuzzy logic
}

Vivek Pandurangan, Om P. Malik

Department of Electrical and Computer Engineering, University of Calgary, Canada

\begin{tabular}{|c|c|}
\hline Article Info & ABSTRACT \\
\hline Article history: & A fuzzy logic based supervisory controller for the multivariable control \\
\hline Received Feb 9, 2019 & $\begin{array}{l}\text { problem in the operation of a cogeneration plant is proposed. Results of } \\
\text { simulation studies with the proposed controller on a dynamic model of the }\end{array}$ \\
\hline Revised Apr 25, 2019 & cogeneration plant show that the plant performs to expectations and tracks \\
\hline Accepted May 12, 2019 & $\begin{array}{l}\text { the set-points in an optimal manner while maintaining critical plant } \\
\text { parameters within limits. }\end{array}$ \\
\hline
\end{tabular}

Keywords:

Supervisory control,

Fuzzy logic,

Cogeneration plant operation.

Copyright $\odot 2019$ Institute of Advanced Engineering and Science. All rights reserved.

\section{Corresponding Author:}

Om P. Malik,

Department of Electrical and Computer engineering,

University of Calgary,

2500 University Drive, N.W., AB T2N 1N4, Canada.

Email: maliko@ucalgary.ca

\section{INTRODUCTION}

Cogeneration systems produce and feed, with improved economics and efficiency, both electric power and process heat within a well-defined boundary that could be a large industrial complex or a district. Economic and efficient operation of a cogeneration system may be divided into an optimization problem and a control problem. Main steps involved in optimizing the plant operation are:

1) Development of an integrated plant optimizer that will calculate the optimal operating condition.

2) Development of a multivariable controller that will take the plant from the present operating condition to the optimal operating point.

The first step includes (i) development of statistical and thermodynamic models and (ii) solution of the optimization problem that is a Mixed Integer Non-Linear Programming problem. Models of a cogeneration facility in a Refinery complex and a district heat and power utility system, and solution of the optimization problem obtained using a custom three stage linear programming approach where the Linear Programming relaxed problem is successively solved in three stages, are presented in [1]. To keep the paper length within reasonable limits, details of this step are not included here as they have already been published.

The primary focus of this paper is the second step, i.e. development of a control system having the following characteristics:

- Take the plant from one operating point to another safely while keeping the deviations of critical plant parameters, such as the desired power, steam header pressure levels and others, to the minimum and within limits.

- Take the plant from one operating point to another within the minimum time possible so that the next optimization run can be scheduled quickly. 
- Be capable of handling system disturbances, such as changes in process power and steam load while keeping the critical system parameters within limits.

- Be a hierarchic high-level supervisory controller and must seamlessly integrate with the existing plant control system.

- Be easy to setup, require minimum system identification tests and should minimize plant downtime during implementation.

Performance of the above tasks requires multi-objective and multi-variable control. Various multivariable control techniques are in use in the industry. Model predictive control (MPC), such as dynamic matrix control (DMC), is extensively used in chemical and petrochemical industries [2-6]. Application of an ad hoc MPC technique using a reduced order non-linear power plant model is reported in [7]. Predictive control techniques like generalized predictive control [8-9], and artificial intelligence control techniques using artificial neural network [10-11], fuzzy logic [12-15] and neuro-fuzzy [16-17] are more common for power plant control.

However, high level controls for cogeneration are rarely discussed in the literature with only a few industrial implementations of high level control for cogeneration systems done using DMC. An example of DMC used for cogeneration is reported in [18].

Considering the multi-control objective specified above, a fuzzy logic based supervisory controller to control the overall operation of the plant is selected in this work. The controller development takes place in the following steps:

- Study of control hierarchy in a modern power plant to answer the question of how and where to integrate the new controller into the existing plant control setup.

- Control modeling to understand the plant dynamics and to decide on the control technique to be used.

- Controller development based on the selected control technique.

- Development of a virtual plant and control environment for simulation and analysis.

The organization of this paper follows lines similar to the above steps. The control hierarchy in a modern process plant is described in section II while the control modeling of equipment in a cogeneration complex is explained in section III. Development of fuzzy logic based supervisory control is detailed in section IV and the effectiveness of the controller through results obtained by simulating the controller in a virtual plant environment is illustrated in section V. Analysis and discussion of the results are given in section VI and the conclusions are summarized in section VII.

\section{CONTROL HIERARCHY}

Modern process and power plants have different levels of control with each level targeting a specific objective. The objectives range from low level plant control to high level performance analysis and report generation. A typical control hierarchy used in modern process plants is shown in Figure 1. The same hierarchy can be successfully applied to a cogeneration system as well.

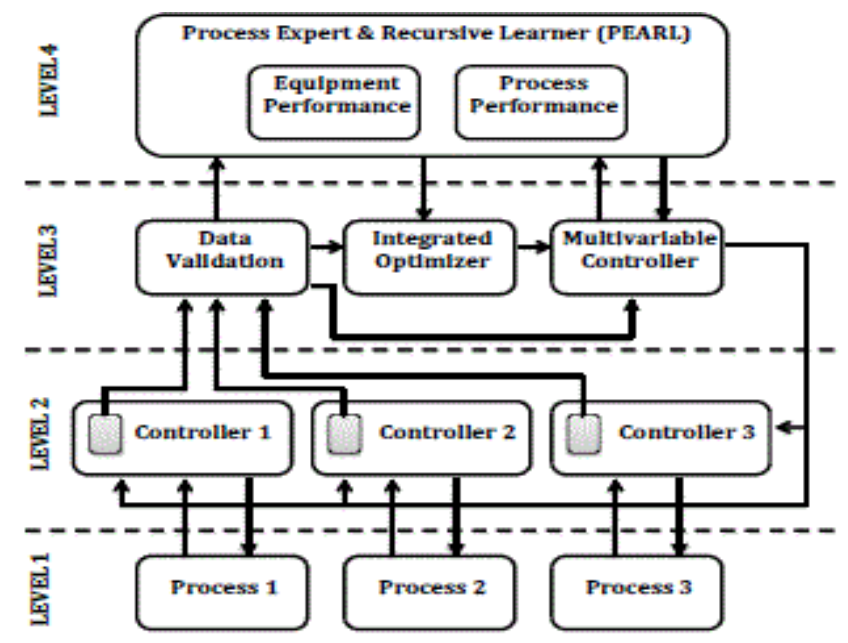

Figure 1. Control hierarchy for a modern process plant 
Level 1 (plant equipment) represents the plant equipment and the field transducers used for controlling and monitoring individual equipment. In the case of the cogeneration system, the plant equipment can be a gas turbine; and the field transducer can be the servo valve used to control the fuel flow to the turbine.

Level 2 (targeted controllers) represents the individual controllers that control a specific equipment or sub-system in the plant. A typical example is a turbine governor system that controls a gas turbine or a steam turbine. Plant Distributed Control System (DCS) also belongs to this category.

Level 3 (optimization and multivariable control) represents the first supervisory control layer in the system. This layer has three main functional modules. First is the data validation module which processes all the plant data, both from the field and the individual controllers; validates the data and passes it on to the optimizer. The data validation is important as the quality of the optimization results depends on the quality of the input data. Second is the integrated optimizer module that collects the plant data from the data validator, the input data and the optimization objectives from the operator, and generates optimal set-points for the real time plant conditions. The objective is usually to minimize the cost, with additional goals depending on how the plant needs to be operated [1]. The third module is multivariable controller that gets the optimal set-points from the optimizer and takes the plant from the present operating condition to the optimal operating condition. The multivariable controller is usually a set-point controller that interfaces directly with the plant low level controllers and the DCS systems. This paper is focused on this module and details of the design and development of a fuzzy supervisory control system are given.

Level 4 (performance monitoring) represents the second supervisory control layer. This layer, also called the enterprise resource layer, is used to present only the most critical plant data to the plant higher management. This data is mostly used by the managers to know about overall plant performance and operation. The long term plant historian is also usually implemented at this level.

\section{CONTROL MODELLING}

Developing a mathematical model of the process is often the first step in control design. Though the design of the fuzzy controller does not depend on internal process models, the models are important tools for the simulation and testing of the controller in an offline environment. Rather than using a detailed dynamic model, relationships between select inputs and outputs in the given system are chosen. This can be observed in the boiler model, where a full model will require relationships to be established between four control loops, namely, air control, feed-water control, attemperator control and fuel flow control. In this study only the fuel control loop is considered as the control affects only this loop. Similar choices are made on all the control models. Though the plant models are dynamic, the steady state nature of the plant models is similar to the optimization models. This can be observed in the boiler models used for optimization and boiler models used for simulation. If in the optimization model the boiler fuel consumption is $10 \mathrm{t}$ for $140 \mathrm{t} / \mathrm{h}$ of steam then the boiler dynamic model will consume the same during steady state conditions. This synchronized characteristic aids accurate real time simulation of the system in conjunction with the optimization of the plant.

Control models for the cogeneration plant components, gas turbine (GT), heat recovery steam generator (HRSG), Boiler, De-aerator, pressure reducer de-superheater (PRDS) and Steam Header have been developed and detailed description of all models is available in [19]. To keep the paper length within limits, only the boiler model is discussed in this section as an illustrative example.

\subsection{Boiler model}

Block diagram of the boiler model is shown in Figure 2. Inputs to the boiler model are boiler steam set-point (SP) and boiler initial conditions while the outputs are boiler steam, boiler fuel consumption and boiler feed water (BFW) consumption. Internally the boiler steam set-point is routed to a rate limiter that controls the rate at which the boiler output can be changed safely. Boilers have high thermal capacitance. Thus fuel input should be changed at a controlled rate so as to achieve a smooth upswing and downswing of the boiler output. The rate limiter helps in achieving the same. The output of the rate limiter is fed to the saturation block that limits the maximum and minimum output from the boiler. Next the signal is given to a second order system with dead-time block that simulates the boiler dynamics. The output of the block is the boiler steam. The module also has a boiler characteristic block that is used for synchronization with the optimization model.

Boiler steam output response to a boiler steam set-point is shown in Figure 3. The boiler set-point is changed from $60 \mathrm{t} / \mathrm{h}$ to $90 \mathrm{t} / \mathrm{h}$ and the steam gradually rises to the set-point in about $200 \mathrm{~s}$; an average increase of $10 \mathrm{t} / \mathrm{h}$ every minute. It can be seen that the swing up has a very flat profile. This can be attributed to the rate limiter in the model. The output begins to rise a good $20 \mathrm{~s}$ after the input is given. This is because 
in an oil fired boiler the air is incremented first and then the fuel. In addition, the large thermal capacitance of the boiler also contributes to this delay.

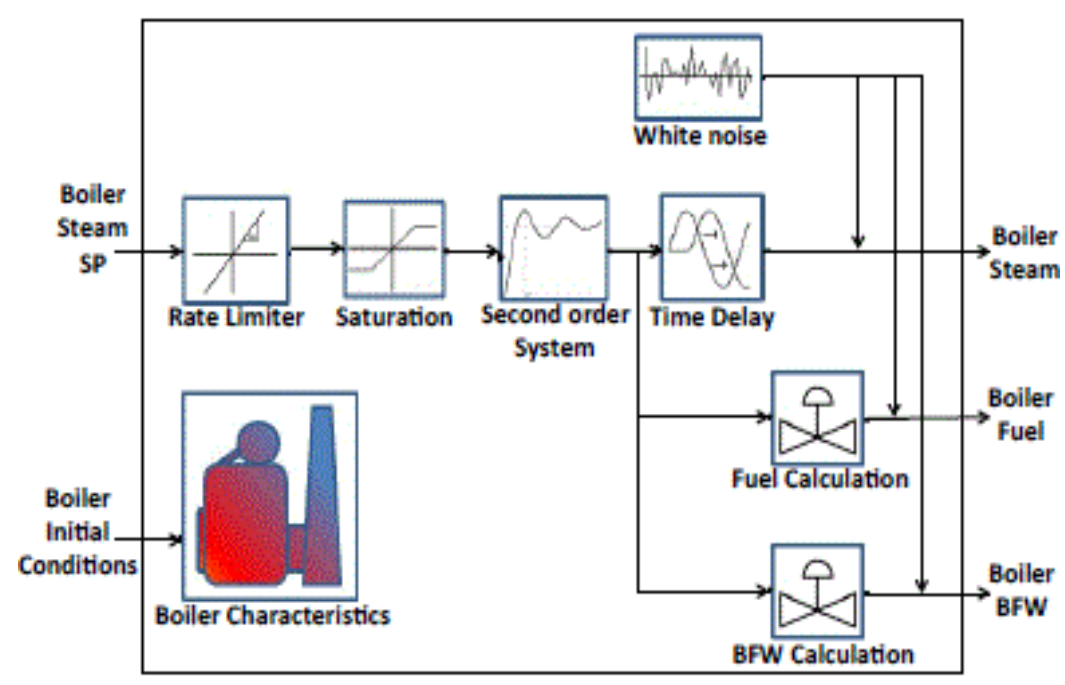

Figure 2. Boiler model (dynamic)

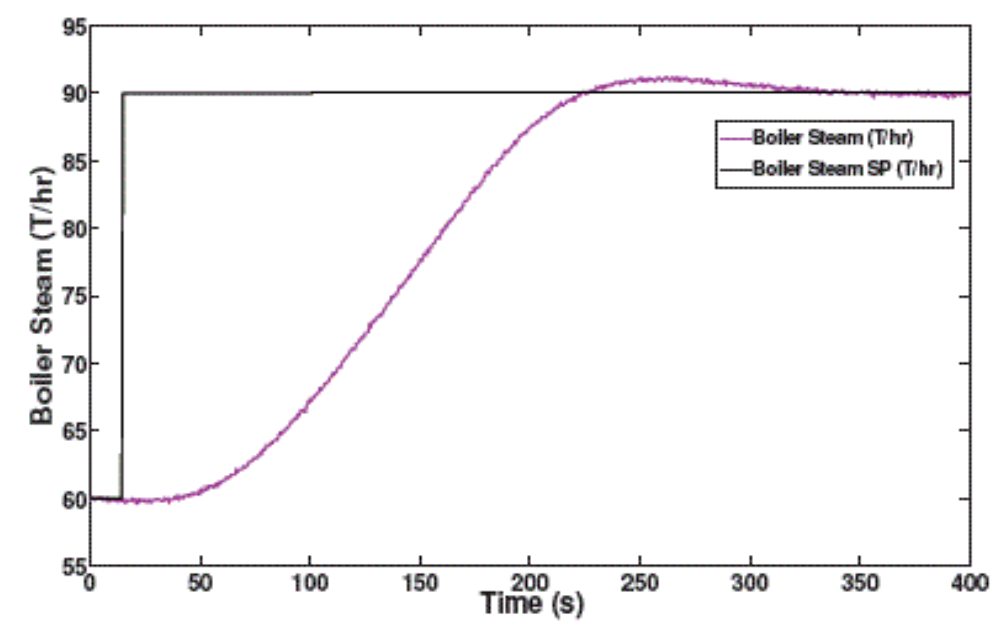

Figure 3. Boiler output characteristics

\section{FUZZY CONTROLLER}

To judge the effectiveness of the selected fuzzy supervisory control system the following critical parameters are taken into account:

a. Optimal set-point deviation for generators and boilers

b. Process settling time

c. Maximum deviation in tie line power level

d. Maximum deviation in steam header pressure level.

In an ideal scenario, deviation from the optimal set-point must be zero under steady state conditions, the process settling time should be as fast as possible, with industry standard time less than thirty minutes, and the maximum deviation of critical parameters levels should be kept less than $10 \%$ of their required operating points. To achieve the control and performance objectives five different fuzzy control schemes have been developed. 
a) Tie Power control scheme:

Any generator in the cogeneration system can operate in tie control mode. In this scheme the generator looks only for the tie power and tries to maintain it at the required operating point. The generator in this mode acts like a slack generator, takes care of the system disturbances and keeps the critical tie line power within limits.

b) Generator set-point control scheme:

Most of the generators in the cogeneration system will operate in the generator set-point control mode. In this mode the fuzzy supervisory control takes the system from the present operating point to the optimal operating point.

c) Steam header pressure control scheme:

Any boiler unit in the cogeneration system can operate in header pressure control mode. In this scheme the boiler tries only to maintain the steam header pressure it controls. The boiler in this mode acts like a slack boiler and takes care of the system disturbances, and keeps the steam header pressure within limits.

d) Boiler set-point control scheme:

Most of the boiler units will operate in the boiler set-point control mode. In this mode the controller takes the boiler from the present operating point to the optimal operating point.

e) PRDS set-point control scheme:

All the PRDSs in the system are put in the PRDS set-point control scheme. In this mode the PRDS not only tries to reach its optimal operating point but also keeps in check the downstream/upstream header pressure.

All five control schemes are used in tandem in the cogeneration plant to achieve the control objectives. The fuzzy rules are designed so that the controller outputs do not conflict with one another. Detailed descriptions of all fuzzy control schemes and the rule bases can be found in [19]. Only the design of generator set-point control is explained below as an illustrative example.

\subsection{Generator set-point control}

The fuzzy generator set-point control scheme is presented in Fig. 4. Inputs to the controller are the tie power set-point error and the generator power set-point error. The generator power set-point error signifies the difference between the optimal operating condition and the present operating condition. This controller is primarily responsible for taking the generator to its optimal operating condition. Generators operating in this mode move towards their optimal set-points and do not care if the load changes happen in the system.

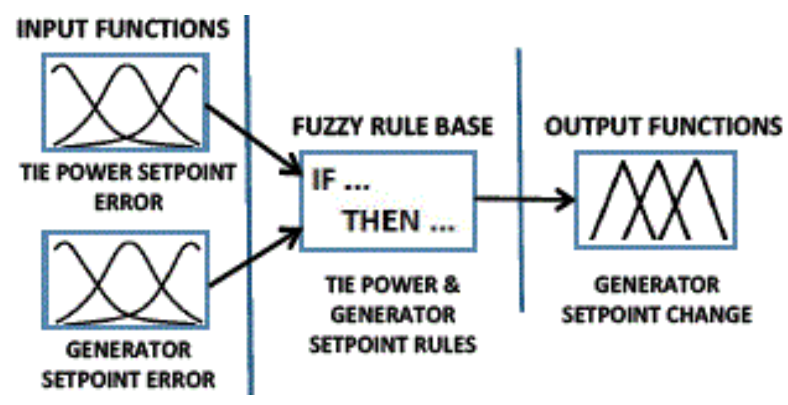

Figure 4. Fuzzy generator set-point control

\section{a. Input and output basis function}

The input and output basis functions are shown in Figure $5 \& 6$, respectively. The range of the input basis functions is chosen in consideration with the maximum allowable tie header error and maximum generator set-point error, while the output basis functions are chosen according to the GT set-point rate limiter. 


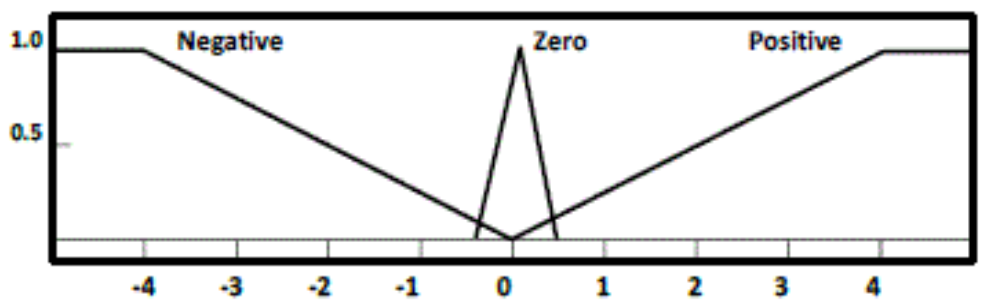

(a)

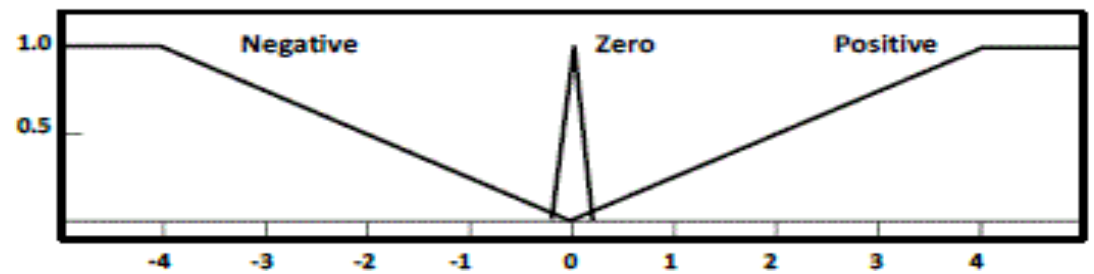

(b)

Figure 5. Input basis functions (Generator set-point control): (a). Power error, (b). Generator set-point error

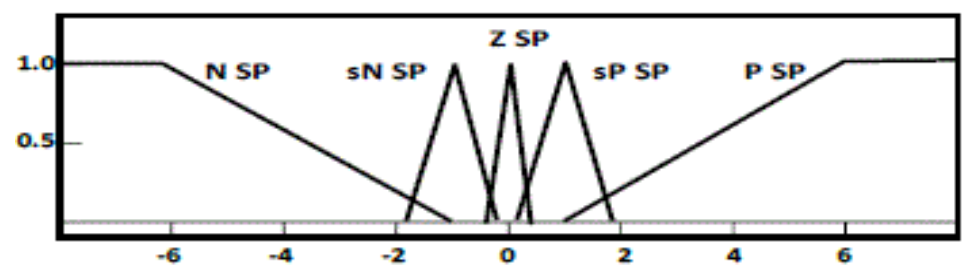

Figure 6. Output basis functions (generator set-point control)

\section{b. Fuzzy rule base}

The fuzzy rule base used in generator set-point control is shown in Figure 7. The fuzzy rule base is designed to mimic an intelligent operator. When both the tie power error and generator set-point error are negative, both errors can be reduced by increasing the set-point of the generator. The fuzzy rule base implements this by giving a positive set-point (P SP). The reverse happens when both the tie power error and generator set-point error are positive. In conditions when the tie power error is positive and generator setpoint error is negative or vice versa, the controller takes no action by giving a Z SP or zero set-point change as any change will aggravate the situation of one of the control parameters. This is explained in the following example.

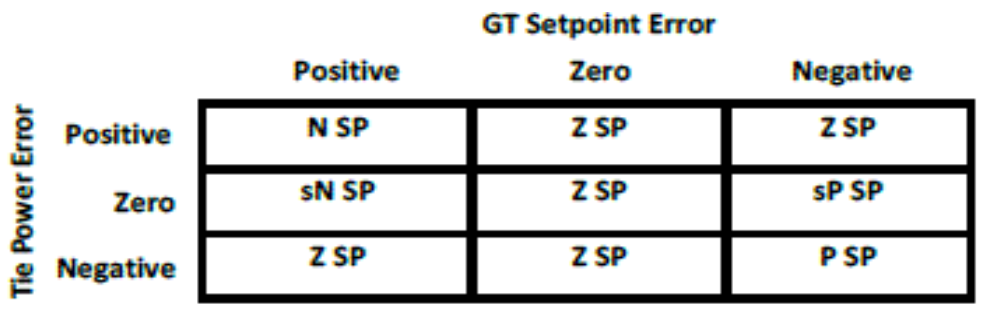

Figure 7. Fuzzy rule base (generator set-point control)

Assume that the tie power error is positive and generator set-point error is negative. If a positive setpoint change is given then generator set-point error will reduce but the critical parameter, tie power error, will increase. Instead, if a negative set-point change is given the tie power error will reduce but the plant will 
move away from the optimal generator operating point. Thus the best course of action is to wait until the conditions become favourable. As the main job of the controller is to take the generator to its optimal operating point, during conditions when the tie power error is zero and there is a positive or negative error generator set-point, it issues a sN SP (small negative set-point) and sP SP (small positive set-point). Any change in the tie power error caused due to this action will be handled by the generator being put in tie power control mode. Finally when both the tie power error and generator power error are zero, the controller gives a zero set-point change as both control objectives are achieved.

\section{c. Control surface}

The control surface for generator set- point controller is shown in Figure 8. It can be observed that when both the generator set-point error and tie power error are positive the generator set-point change is negative. When both the generator set-point error and tie power error are negative the generator set-point change is positive. It can be seen that the control surface output is non-zero at zero tie power error conditions. This is due to the small set-point changes specified in the fuzzy rules. In conditions when tie power error and generator set-point error are of opposite sign a zero set-point change is the output.

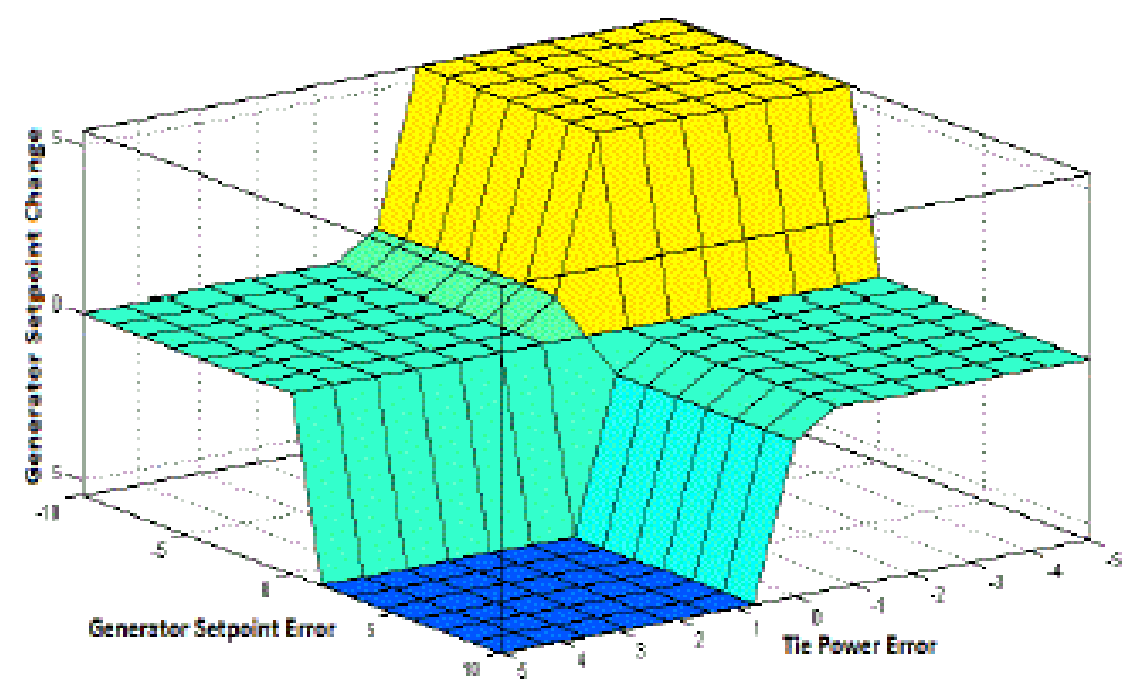

Figure 8. Control surface (generator set-point control)

\section{SIMULATION STUDIES AND RESULTS}

To simulate the control developed, a virtual plant environment is created as shown in Fig. 9. The model plant used to test the fuzzy control is the same refinery cogeneration plant as used to test the optimization algorithm [1]. The plant consists of three GT-HRSG units, three boiler units, three steam headers and three PRSD units. The non-optimized initial conditions are defined in a plant Graphical User Interface (GUI) developed in excel. The plant initial conditions are used by the integrated optimizer [1] to come up with the optimal set-points. The optimal set-points are used by the real time plant model in Simulink to simulate the control action. A full battery of control tests, namely,

- Optimal operating point tracking test

- Power disturbance test

- Steam disturbance test

- Evolving load test

- Partial control failure test

It was conducted to test the efficacy of the proposed controller. Results of simulation studies for all the above mentioned tests are de-tailed in [19]. Results of two tests, the optimal operating point tracking test where the controller takes the point from an initial operating point to an optimized operating point and the power disturbance test where the system experiences a sudden power load change, are given below as an illustration of the performance obtained. 


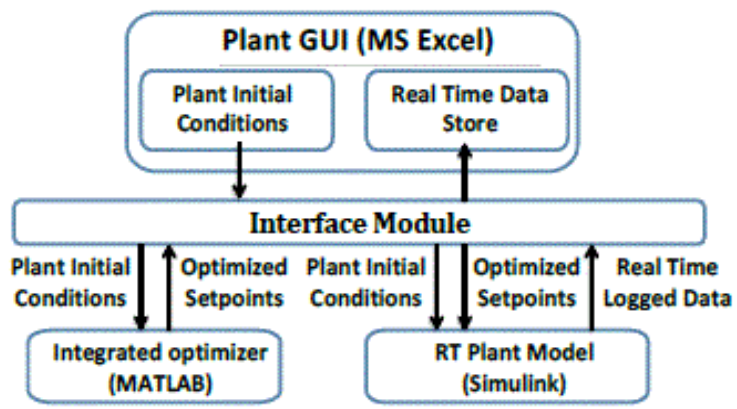

Figure 9. Virtual plant environment

\subsection{Simulation with optimization parameters}

The plant initial conditions and the plant optimal operating point are shown in Table 1. The supervisory control used to control the plant consists of nine individual fuzzy controllers; one each for three gas turbines, one each for three boilers and one each for three PRDSs. GT-1 and GT-3 were operated in generator set-point control mode while GT-2 was put in the tie power control mode. Boiler-1 and Boiler-3 were operated in boiler set-point control mode while Boiler-2 was put in the header pressure control mode. All the PRDSs were put in PRDS set-point control mode. The simulation ran for $1500 \mathrm{~s}$ in the real time plant model developed in SIMULINK. The results are shown in Table 1.

Table 1 Plant Initial Conditions and Optimal Operating Point

\begin{tabular}{|c|c|c|c|}
\hline \multicolumn{2}{|c|}{ Plant Equipment Parameters } & Initial Plant Conditions & Optimized Plant Conditions \\
\hline \multirow{13}{*}{ Plant equipment parameters } & GT-1 Power & $16 \mathrm{MW}$ & $8 \mathrm{MW}$ \\
\hline & GT-2 Power & $16 \mathrm{MW}$ & $18 \mathrm{MW}$ \\
\hline & GT-3 Power & $16 \mathrm{MW}$ & $22 \mathrm{MW}$ \\
\hline & HRSG-1 HP Steam & $33 \mathrm{t} / \mathrm{h}$ & $21 \mathrm{t} / \mathrm{h}$ \\
\hline & HRSG-1 MP Steam & $4.5 \mathrm{t} / \mathrm{h}$ & $3.7 \mathrm{t} / \mathrm{h}$ \\
\hline & HRSG-2 HP Steam & $33.5 \mathrm{t} / \mathrm{h}$ & $36.5 \mathrm{t} / \mathrm{h}$ \\
\hline & HRSG-2 MP Steam & $4.6 \mathrm{t} / \mathrm{h}$ & $4.8 \mathrm{t} / \mathrm{h}$ \\
\hline & Boiler-1 MP Steam & $90 \mathrm{t} / \mathrm{h}$ & $120 \mathrm{t} / \mathrm{h}$ \\
\hline & Boiler-2 MP Steam & $90 \mathrm{t} / \mathrm{h}$ & $104 \mathrm{t} / \mathrm{h}$ \\
\hline & Boiler-3 MP Steam & $75.5 \mathrm{t} / \mathrm{h}$ & $30 \mathrm{t} / \mathrm{h}$ \\
\hline & PRDS-1 Downstream Steam & $34.5 \mathrm{t} / \mathrm{h}$ & $63 \mathrm{t} / \mathrm{h}$ \\
\hline & PRDS-2 Downstream Steam & $28 \mathrm{t} / \mathrm{h}$ & $0 \mathrm{t} / \mathrm{h}$ \\
\hline & PRDS-3 Downstream Steam & $112 \mathrm{t} / \mathrm{h}$ & $140 \mathrm{t} / \mathrm{h}$ \\
\hline \multirow{4}{*}{ Critical plant parameters } & Tie Power & $0 \mathrm{MW}$ & $0 \mathrm{MW}$ \\
\hline & HP Steam Header Pressure & $50 \mathrm{~kg} / \mathrm{cm} 3$ & $50 \mathrm{~kg} / \mathrm{cm} 3$ \\
\hline & MP Steam Header Pressure & $14 \mathrm{~kg} / \mathrm{cm} 3$ & $14 \mathrm{~kg} / \mathrm{cm} 3$ \\
\hline & LP Steam Header Pressure & $5 \mathrm{~kg} / \mathrm{cm} 3$ & $5 \mathrm{~kg} / \mathrm{cm} 3$ \\
\hline \multirow{4}{*}{ Process power \& steam loads } & Process Power Load & $48 \mathrm{MW}$ & $48 \mathrm{MW}$ \\
\hline & Process HP Steam Load & $50 \mathrm{t} / \mathrm{h}$ & $50 \mathrm{t} / \mathrm{h}$ \\
\hline & Process MP Steam Load & $138 \mathrm{t} / \mathrm{h}$ & $138 \mathrm{t} / \mathrm{h}$ \\
\hline & Process LP Steam Load & $140 \mathrm{t} / \mathrm{h}$ & $140 \mathrm{t} / \mathrm{h}$ \\
\hline
\end{tabular}

The tie and GT power changes during the simulation are shown in Figures 10 and 11, respectively. It is observed that, from the initial condition of $16 \mathrm{MW}, \mathrm{GT}-3$ reaches its optimal operating point in about $100 \mathrm{~s}$. During this time GT-1 load is going down, but with no generator able to match the power reduction the tie power also begins to go negative as seen in Figure 10. Now GT-2 that is in the tie power control mode comes into play and increases its power output. Thus as GT-1 lowers its output GT-2 increases its own to keep the tie power at a constant level. All GTs reach their optimal operating point in about $180 \mathrm{~s}$. It is observed that the maximum deviation in the tie power is only $0.4 \mathrm{MW}$ that is well within the required control range. 


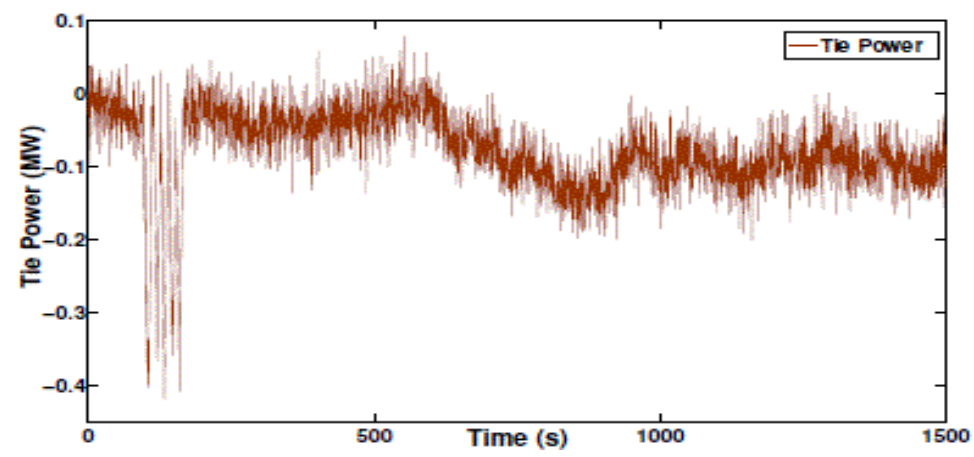

Figure 10. Tie power

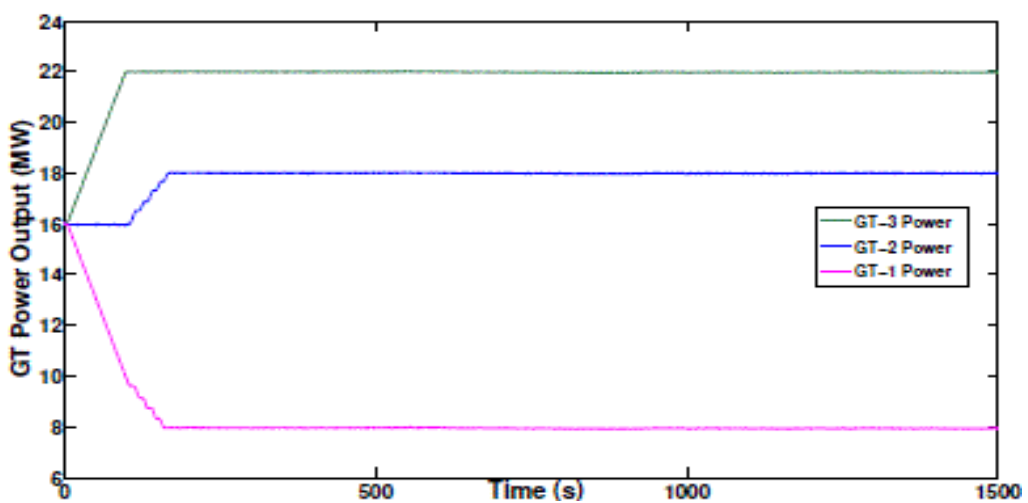

Figure 11. GT power

The HP header pressure, and the major steam inflow and outflow from the HP header are shown in Figures 12 and 13, respectively. HRSG- 1, HRSG-2 and HRSG-3 HP steam represent the major steam inflow into the header, while PRDS-1 and PRDS-2 represent upstream flow, and HP process load represents the major steam outflow. It is observed that the HRSG steam follows the GT power variations and settles in less than $240 \mathrm{~s}$. The PRDS flow is usually dependent on the downstream pressure regulation and settles at around $1000 \mathrm{~s}$. About the same time the header pressure also stabilizes at $50 \mathrm{~kg} / \mathrm{cm}^{\wedge}$, which is the required operating point of the header. It is observed that though there are significant changes in inflow and outflow, the maximum header pressure variation is positive $0.25 \mathrm{~kg} / \mathrm{cm}^{2}$ that is well within the required operational limits.

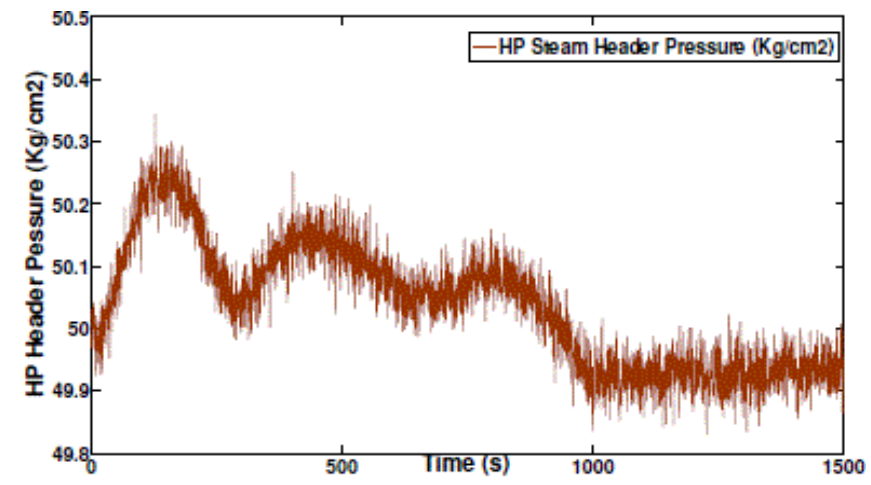

Figure 12. HP header pressure 


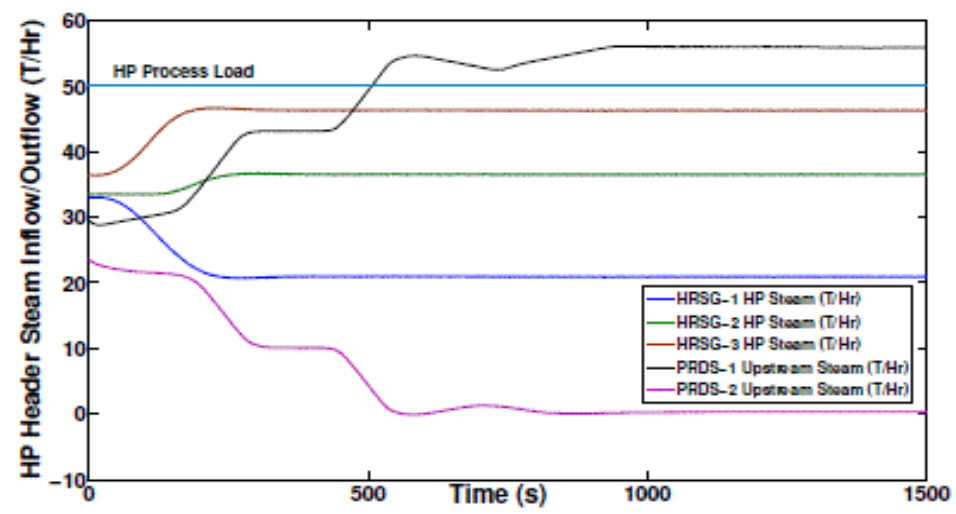

Figure 13. HP header flow

The MP steam header pressure, and the major inflow and outflow from the MP header are shown in Figures 14 and 15, respectively. Boiler-1, Boiler-2, Boiler-3 and PRDS-1 Downstream steam represent the major inflow while MP process steam load and the PRDS- 3 Upstream Steam represent the major outflow from the MP header. It can be seen that Boiler-1 and Boiler-3 swing to their optimal set-point and reach their optimal set-points in $800 \mathrm{~s}$ and $1200 \mathrm{~s}$, respectively. It can be observed that Boiler-2 that is in the header pressure control mode increases its output when the header pressure goes low and reduces its output when the header pressure goes high. As the MP process load remains the same throughout, Boiler-2 finally settles at its optimal operating point at around $1400 \mathrm{~s}$. About the same time the MP header pressure settles at $14 \mathrm{~kg} / \mathrm{cm}^{2}$ which is the required operating point. It is seen that even with large steam swings in the boilers and the PRDS the controllers work well and the critical steam pressure is controlled well. During the whole simulation period the MP header pressure had a maximum positive deviation of $0.4 \mathrm{~kg} / \mathrm{cm}^{2}$ and maximum negative deviation of $0.4 \mathrm{~kg} / \mathrm{cm}^{2}$; well within the required operational limits.

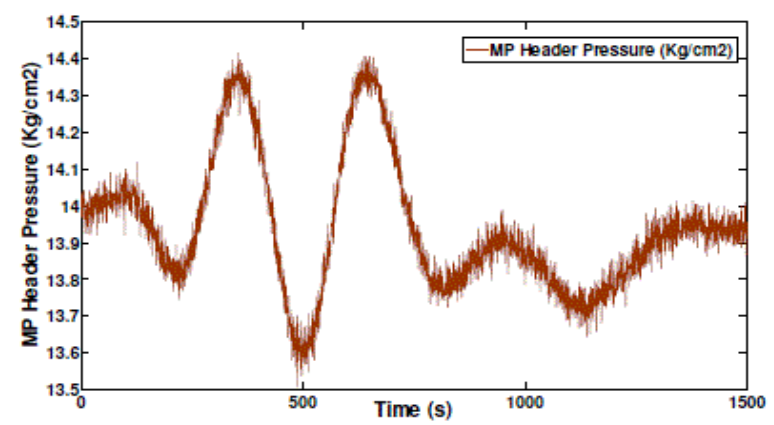

Figure 14. MP header pressure

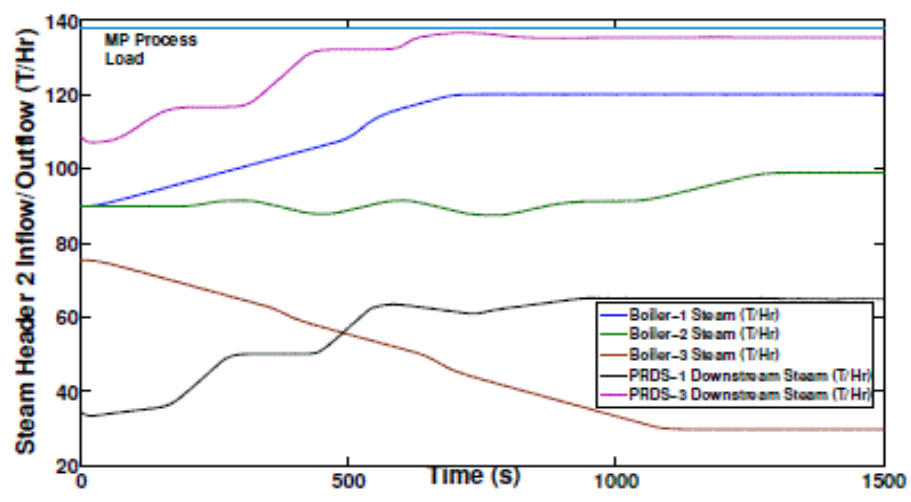

Figure 15. MP header flow 
The LP header pressure, and the major inflow and outflow from the LP steam header are shown in Figure 16 \& 17, respectively. PRDS-2 and PRDS-3 downstream steam flow represents the major inflow into the header while LP process steam load represents its major outflow. It is observed that the PRDSs reach their steady state conditions in about $800 \mathrm{~s}$ and at about the same time the header pressure also stabilizes to $5 \mathrm{~kg} / \mathrm{cm}^{2}$, the required operating point. It is seen that the PRDS controllers work well and the maximum positive deviation in header pressure is only about $0.25 \mathrm{~kg} / \mathrm{cm}^{2}$ and maximum negative deviation is about $0.2 \mathrm{~kg} / \mathrm{cm}^{2}$; well within the operational limits.

The boiler fuzzy controller outputs and real time boiler output during the simulation studies are shown in Figure 18. Here too the controllers provide well matched outputs. Minimal amount of control jitter can be found in Boiler-2 performance, but that is due to the fact that the header pressure measurement had a high level of Gaussian noise and the controller was designed with minimal dead bands.

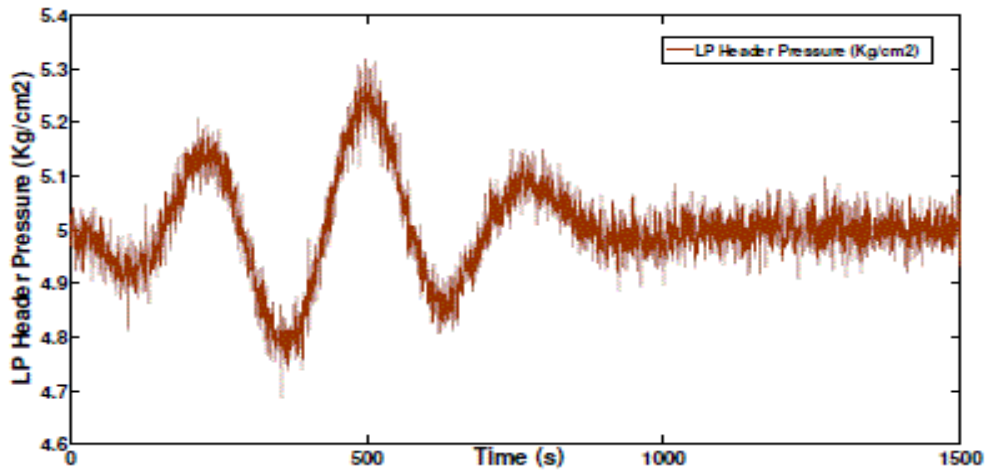

Figure 16. LP header pressure

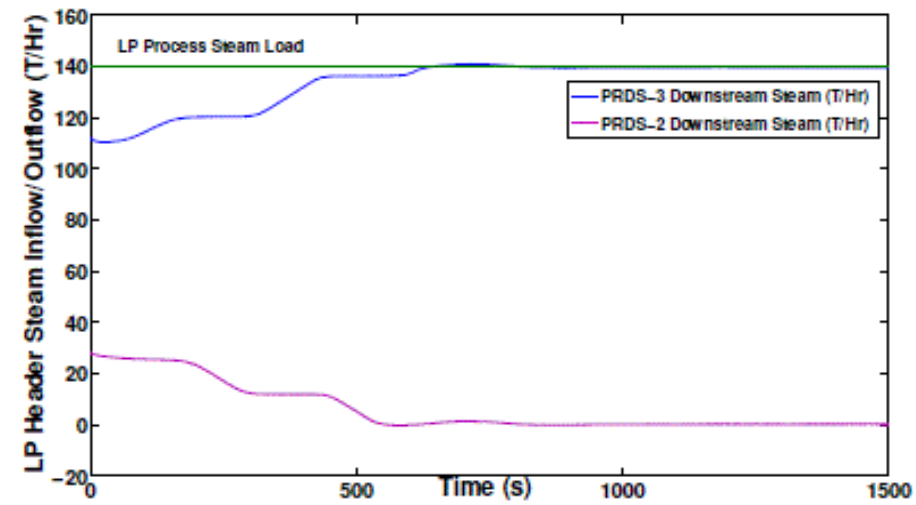

Figure 17. LP header flow

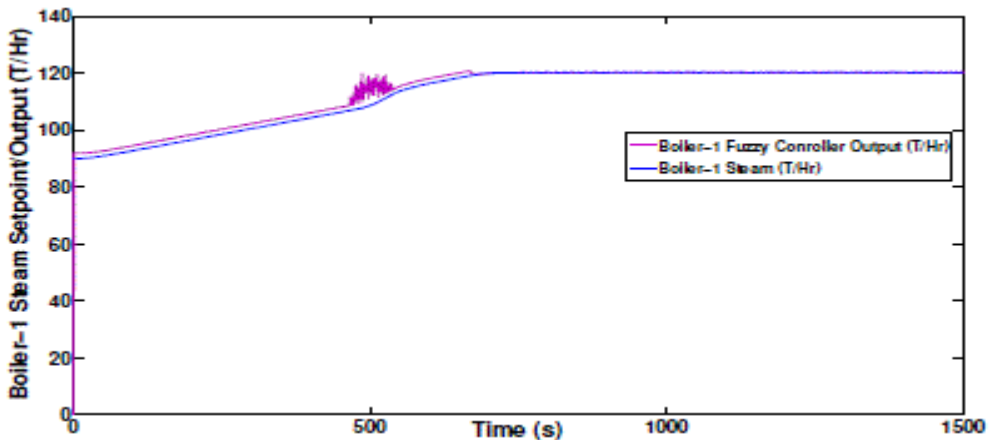

(a) 


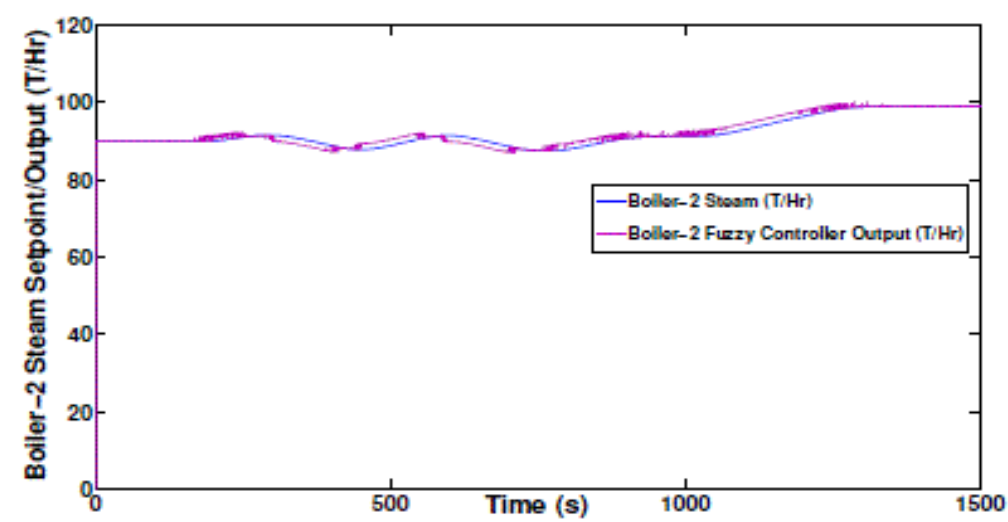

(b)

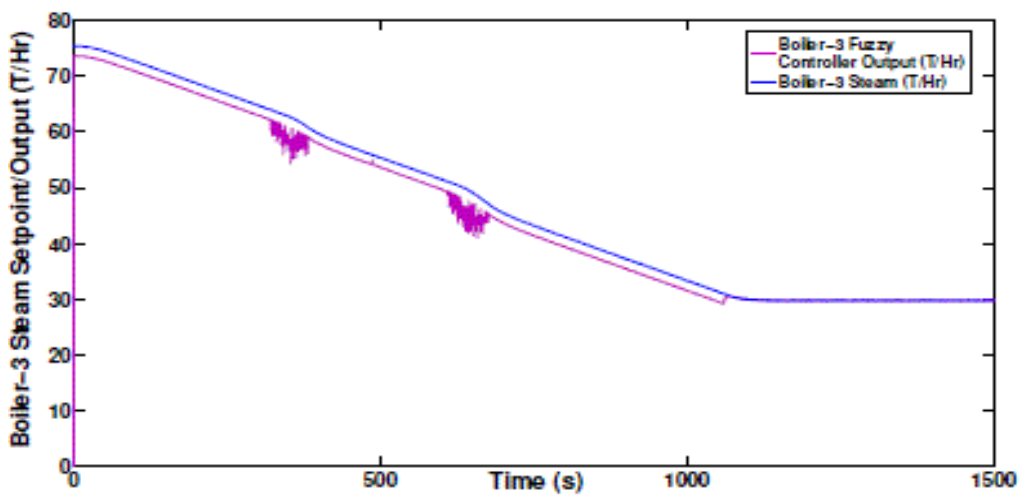

(c)

Figure 18. Fuzzy controller vs. real-time output (boilers): (a) Boiler 1- steam set-point output, (b) Boiler 2-steam set-point output, (c) Boiler 3-steam set-point output

\subsection{Simulation with changes in power loads}

The controller behaviour when a process power load change takes place in between optimization runs is discussed here.

Changes in (a) process load, (b) tie power and (c) GT power swing during simulation with varying process power load are shown in Fig. 19. From the initial condition where the process load is $45 \mathrm{MW}$ and all the GTs are loaded to $15 \mathrm{MW}$ each, GT-1 reduces to $10 \mathrm{MW}$, GT-2 increases to $17 \mathrm{MW}$ and GT-3 increases to $18 \mathrm{MW}$ in accordance with the optimized set-point values. In the simulation GT-1 and GT- 3 operate in setpoint control mode while GT-2 is put in the tie power control mode. At time $150 \mathrm{~s}$ the process load suddenly increases to $48 \mathrm{MW}$, a process load increase of $3 \mathrm{MW}$ and the tie power goes to an import of $3 \mathrm{MW}$. Now GT-2 takes action and increases its power output from $17 \mathrm{MW}$ to $20 \mathrm{MW}$, pushing the tie power back to the required operating value of $0 \mathrm{MW}$ in about $40 \mathrm{~s}$. At time $220 \mathrm{~s}$ the process load falls to $42 \mathrm{MW}$ and the tie power goes to an export of $6 \mathrm{MW}$. Now GT-2 reduces its power to $14 \mathrm{MW}$ to push the tie power to zero MW in about $70 \mathrm{~s}$. During the load changes it is observed that the generators that are in the power set-point control mode do not come into play and maintain their optimal operating point while GT-2 takes care of the load changes. 


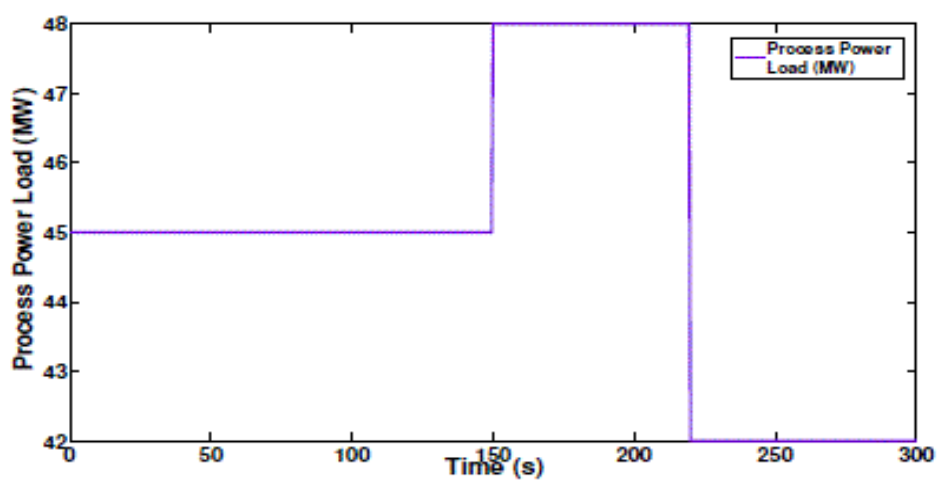

Figure 19 (a). Process load change

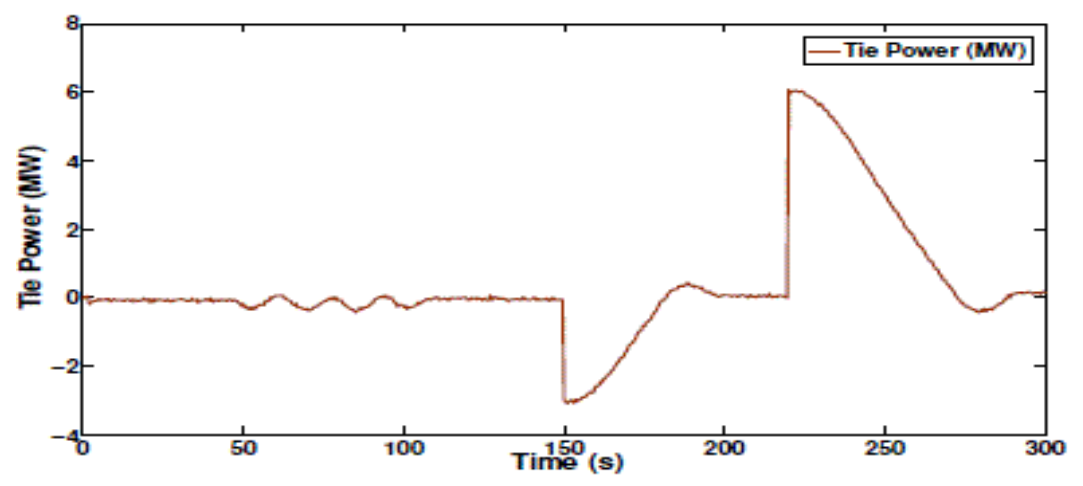

Figure 19 (b). Tie power

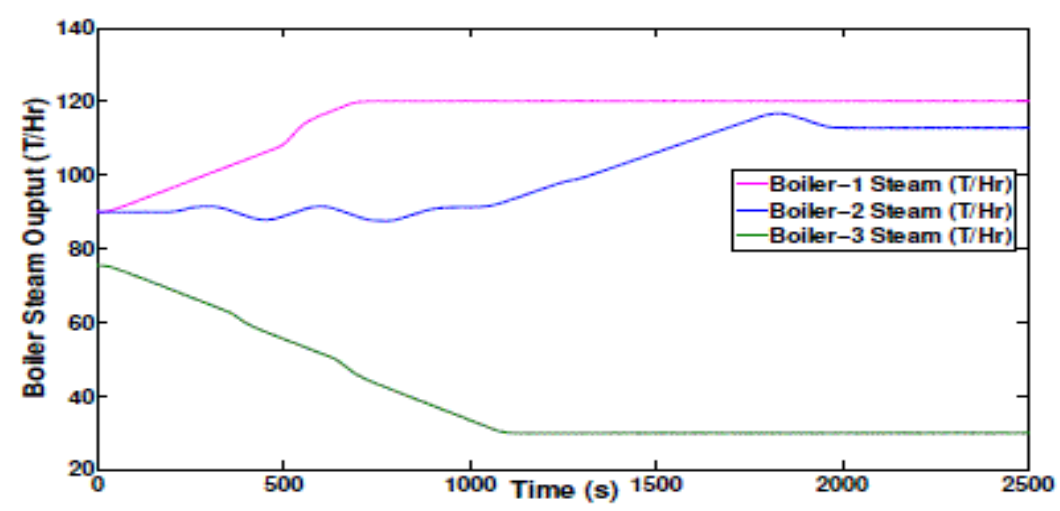

Tie power (c). GT power

Figure 19. Simulation with power load change: (a) Process load change, (b) Tie power, (c) GT power

\section{ANALYSIS AND DISCUSSION}

It is observed in the simulation studies that the controller performs well when transferring the plant from the initial operating condition to the optimal operating point. Though the generator and boiler output changes are significant, the controllers manage to stabilize the plant in about $20 \mathrm{~m}(1200 \mathrm{~s})$. It is also seen that even though as many as nine different controllers in more than 5 different operational modes are used, the controllers worked in tandem to achieve the control objectives. Not only does the plant reach optimal operating conditions in a short period of time, the critical plant parameters were also maintained. The high level control of co-generation plants having hardly ever been reported in the literature, no data for comparison is available.

The generator set-point controller takes the GTs to their operating point within $180 \mathrm{~s}$ and the tie line power controller aided by the generator set-point controller keeps the maximum deviation in the tie line 
power to a bare minimum of -0.4 MW. The boiler set-point controller took the boilers to their optimal operating point in about $1200 \mathrm{~s}$. This $1200 \mathrm{~s}$ time interval is needed due to the large change in the steam output. Even with the huge steam inflow/outflow changes, the header pressure controller, used to control the MP header, works well, with a maximum positive and negative deviation of $0.4 \mathrm{~kg} / \mathrm{cm}^{2}$; a $2.8 \%$ change from normal operating condition. The PRDS set-point controller also does well both taking the PRDS to its operating point as well as maintaining the downstream header pressure. This can be seen in the LP header where both PRDS-2 and PRDS-3 are controlling the header pressure. The LP header pressure has a maximum positive and negative deviation of $0.2 \mathrm{~kg} / \mathrm{cm} 2$; a $4 \%$ change from nominal operating condition. It is also seen that the maximum positive and negative pressure deviation in the HP header is about $0.2 \mathrm{~kg} / \mathrm{cm}^{2}$; a $0.4 \%$ change from nominal operating condition.

The controller also performs well in plant disturbance tests. When the plant power load is changed, the tie controller comes into action and takes the tie power from a positive or negative import condition to zero tie power level. Similarly when the process steam load is changed, the header pressure controller comes into action and maintains the header pressure at its nominal operating value. Thus the control scheme maintains the plant critical parameters even during process load changes.

\section{CONCLUSION}

As mentioned in the Introduction, high level control of co-generation plants, discussed here, is hardly ever reported in the literature. In that way, this paper makes a unique contribution. The supervisory fuzzy set-point controller proposed here performed to expectations by successfully tracking the optimal set-points in a complex cogeneration plant model. The control matched or exceeded the performance parameters and most importantly maintained critical plant parameters. The importance of the fuzzy controller lies in its ease of use and scalability. As the fuzzy controller works with predetermined rule base it does not need any system identification tests, thus significantly reducing deployment time and engineering costs. As the main supervisory control is made of independent sub-controllers with specific tasks and deployment equipment, the control can be easily scaled depending on the type and number of equipment present in the plant. Also, the fuzzy supervisory control being a set-point controller can be easily integrated into the existing plant DCS or control equipment.

In addition, the dynamic modelling of plant equipment and headers is accomplished to create a virtual cogeneration system that has been used to test the plant high level control. As with optimization models, the dynamic models developed here can be reused in future research work and the simulation platform developed can be easily extended to accommodate newer plant and control models.

\section{REFERENCES}

[1] V. Pandurangan and O. Malik, "Optimization of co-generation system operation," 2014 6th IEEE Power India International Conference (PIICON), Delhi, 2014, pp. 1-6.

[2] Garcia, C.E, Prett, D.M, Morari, M, "Model Predictive Control: Theory and Practice - A Survey," Automatica, vol. 25, pp. 335-348, 1989.

[3] Mayne, D.Q, Rawlings, J.B, Rao, C.V, Scokaert, P.O.M, "Constrained model predictive control: Stability and optimality," Automatica, vol. 36, pp. 789-814, 2000.

[4] Camacho, E.F, Bordons, C, "Model Predictive Control in the Process Industry," Springer: Berlin, 1999.

[5] Maciejowski, J, Predictive Control with Constraints, Prentice-Hall: Englewood Cliffs, NJ, 2001.

[6] Qin, S.J, Badgwell, T.A, "An overview of industrial model predictive control technology," Fifth International Conference on Chemical Process Control, pp. 232-256, 1996.

[7] Lu, S, Hogg, B.W, "Predictive coordinated control for power-plant steam pressure and power output," Control Engineering Practice, vol. 5, no. 1, pp.79-84, 1997.

[8] Andrzej Krolikowski, "Adaptive Generalized Predictive Control Subject to Input Constraints," Proceedings of the 7th Mediterranean Conference on Control and Automation, pp. 54-61, 1999.

[9] Krolikowski, A., Jerzy, D., "Self-Tuning Generalized Predictive Control With Input Constraints," Int. J. Appl. Math. Comput. Sci., vol. 11 , no. 2, pp. 459-470, 2001.

[10] Prasad, G., Swidenbank, E., Hogg, B.W., "A neural net model-based multivariable long-range predictive control strategy applied in thermal power plant control," IEEE Transactions on Energy Conversion, vol. 13, no. 2, pp. 176-182, 1997.

[11] Prasad, G., Irwin, G.W., Swidenbank, E., Hogg, B.W., "Plant-wide predictive control for a thermal power plant based on a physical plant model," IEEE Proceedings on Control Theory Applications, vol. 147, no. 4, pp. 523-537, 2000.

[12] Yukita, K., Goto, Y., Mizuno, K., Miyafuji, T., Ichiyanagi, K., Mizutani, Y., "Study of load frequency control using fuzzy theory by combined cycle power plant," IEEE Power Engineering Society Winter Meeting, 2000, vol. 1, pp $.422-427,2000$. 
[13] Pruessmann, D., Krause, B., von Altrock, C., "Fuzzy logic supervisory control for coal power plant," Fuzzy Systems, 1997, Proceedings of the Sixth IEEE International Conference, vol.2, pp. 921-925, 1997.

[14] Garduno-Ramirez, R., Lee, K.Y., "Wide range operation of a power unit via feedforward fuzzy control [thermal power plants]," IEEE Transactions on Energy Conversion, vol.15, no. 4, pp .421-426, 2000.

[15] Garduno-Ramirez, R., Lee, K.Y., "Fuzzy scheduling control of a power plant," IEEE Power Engineering Society Winter Meeting, vol. 1, pp. 441-445, 2000.

[16] Brown, M., Harris, C.J., "Neuro-fuzzy Adaptive Modelling and Control," Englewood Cliffs, NJ: Prentice-Hall, 1994.

[17] Liu, X.J., Lara-Rosano, F., Chan, C.W., "Neuro fuzzy network modelling and control of steam pressure in 300MW steam-boiler sys- tem, " Engineering Applications of Artificial Intelligence, vol. 16, no. 5, pp. 431-440, 2003.

[18] Goodhart, S., Nishizawa," J., Yano, K., Yada, H., "Advanced control in cogeneration utility management", Computing and Computer Engineering Journal, vol. 1, pp. 273-282, 2000.

[19] Pandurangan, V., "Optimization and Supervisory Control of Cogeneration Systems," M.Sc. Thesis, University of Calgary, 2013.

\section{BIOGRAPHIES OF AUTHORS}

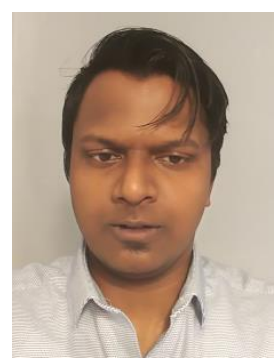

Vivek Pandurangan obtained his B.Tech. from College of Engineering, Trivendram, India, in 2008 and the M.Sc. from the University of Calgary, Calgary, Canada, both in electrical engineering in 2008 and 2013, respectively. He worked in the industry from 2008 to 2011 and has been working in the industry since 2013 .

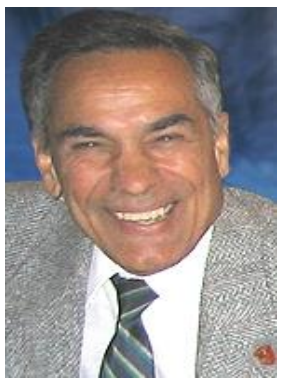

Om P. Malik received the National Diploma in electrical engineering from Delhi Polytechnic, Delhi, India, in 1952, the M.E. degree in electrical machine design from Roorkee University, Roorkee, India in 1962, and the Ph.D. degree from the University of London, London, U.K. and the Diploma of the Imperial College of the Imperial College of Science and Technology, London, in 1965. He became a Professor in the Department of Electrical and Computer Engineering, University of Calgary, Calgary, Canada, in 1974 where he is currently a Professor Emeritus. He has been engaged in research in collaboration with industry and teams from many countries in the areas of adaptive control and protection of power systems, and generation of electricity from renewable sources. He has served in many additional capacities at the University of Calgary including Associate Dean Academic and Student affairs, and Acting Dean of the Faculty of engineering. 